\title{
Profissionais de apoio à inclusão escolar: motivos para demandas e atribuições
}

\author{
Support professionals for school inclusion: reasons \\ for demands and assignments
}

\section{Profesionales de apoyo a la inclusión escolar: motivos de demandas y asignaciones}

\author{
Mariana Moraes Lopes 1 \\ https://orcid.org/0000-0002-4688-5I 29 \\ Enicéia Gonçalves Mendes 2 \\ https://orcid.org/0000-00033673-068I
}

\begin{abstract}
Resumo: A literatura recomenda diferentes profissionais para compor as redes de apoio à inclusão escolar e, no Brasil, nota-se a crescente demanda, por parte de familiares e educadores, do denominado Profissional de Apoio à Inclusão Escolar (PAIE). O presente estudo teve como finalidade descrever e analisar motivos alegados nas demandas por PAIE nas escolas para apoiar estudantes do Público-Alvo da Educação Especial (PAEE). $O$ método multicasos envolveu 30 PAIE de cinco municípios de dois estados brasileiros (três do Estado da Bahia e dois do Estado de São Paulo). Os resultados evidenciaram cinco categorias de justificativas, a saber: I) promover participação e aprendizagem dos estudantes PAEE; 2) prover suporte em casos de estudantes PAEE com comportamentos desafiadores; 3 ) prover suporte pedagógico às necessidades de estudantes com impedimentos motores; 4) prover suporte nos cuidados pessoais básicos (higiene pessoal, locomoção e alimentação) e; 5) prover suporte para evitar que o estudante PAEE atrapalhe sua turma, retirando-o da sala de aula. Conclui-se que algumas dessas justificativas são justificadas, enquanto que outras encobrem mecanismos de exclusão e políticas de barateamento dos suportes profissionais, e que a judicialização das demandas pode estar contribuindo para assim as manter.
\end{abstract}

Palavras-chave: Educação Especial. Profissional de Apoio à Inclusão Escolar. Atribuição.

Abstract: The literature recommends different professionals to compose the support networks for school inclusion, and in Brazil, there is a growing demand by family members and educators for the so-called Professional Support for School Inclusion (PSSI). This study aimed to describe and analyze the reasons alleged in the demands for PSSI in schools, to support students with Special Educational Needs (SEN). The multi-case study involved 30

\footnotetext{
${ }^{1}$ Doutoranda no Programa de Pós-Graduação em Educação Especial da Universidade Federal de São Carlos, Mestre em Educação Especial (UFSCar). E-mail: mamarylopesedespecial@gmail.com

2 Doutora em Psicologia (USP), Professora Titular do Departamento de Psicologia do Programa de PósGraduação em Educação Especial da Universidade Federal de São Carlos. E-mail: egmendes@ufscar.br
} 
PSSI from five municipalities in two Brazilian states (three in the State of Bahia and two in the State of São Paulo). The results showed five categories of justifications, namely: I) to promote the participation and learning of SEN students; 2) to provide support for students with challenging behaviors, 3) to provide pedagogical support for students with motor impairments; 4) to provide support in basic personal care (personal hygiene, locomotion and food), and 5) to prevent SEN students from interfering with the class by removing him from the classroom. We concluded that some of these justifications, while covering up exclusion mechanisms and policies to lower cost of professional support, and the results of judicialization of demands have helped to maintain them.

Keywords: Special Education. Support Professional for School Inclusion. Assignment.

Resumen: La literatura recomienda diferentes profesionales para componer redes de apoyo para la inclusión escolar y, en Brasil, existe una demanda creciente, por parte de familiares y educadores, del llamado Profesional de Apoyo a la Inclusión Escolar (PAIE). Este estudio tuvo como objetivo describir y analizar las razones alegadas en las demandas del PAIE. El método de casos múltiples involucró 30 PAIE de cinco ciudades de dos estados brasileños, tres ciudades del estado de la Bahía y dos del estado de São Paulo. Los resultados mostraron cinco categorías de justificaciones, a saber: I) promover la participación y el aprendizaje de los estudiantes con NEE; 2) brindar apoyo en caso de estudiantes con NEE con conductas desafiantes; 3) brindar apoyo pedagógico a las necesidades de los estudiantes con discapacidades motoras; 4) brindar apoyo en el cuidado personal básico (higiene personal, movilidad y alimentación) y; 5)brindar apoyo para evitar que el alumno con NEE interfiera con la clase, sacándolo del aula. Se concluye que algunas demandas son justificadas, mientras que otras encubren mecanismos de exclusión y políticas para bajar el costo del acompañamiento, y que los resultados de la judicialización han contribuido a mantener.

Palabras-clave: Educación Especial. Profesional de apoyo a la inclusión escolar. Asignación.

\section{Introdução}

A educação é direito universal e inegociável, porém, para que seja materializado esse direito, é necessário a superação de barreiras e refletidas as possibilidades para serem atendidas as singularidades existentes em turmas heterogêneas. No Plano Nacional de Educação (PNE), aprovado por meio da Lei $n^{\circ}$ 13.005/2014, estabeleceram-se diretrizes e metas em âmbito nacional, estadual e municipal a serem atingidas em uma década, visando o desenvolvimento da educação nacional. Na meta 4, referente à Educação Especial, foi definido:

\footnotetext{
Universalizar, para a população de 4 (quatro) a 17 (dezessete) anos com deficiência, transtornos globais do desenvolvimento e altas habilidades ou superdotação, o acesso à educação básica e ao atendimento educacional especializado, preferencialmente na rede regular de ensino, com a garantia de sistema educacional inclusivo, de salas de recursos multifuncionais, classes, escolas e serviços especializados, públicos ou conveniados (BRASIL, 2014, on-line).
}

Frente ao apresentado e considerando a necessidade de colocar em prática um direito garantido, a literatura aponta a importância da construção de estratégias e serviços que atendam a diversidade. Para que isso ocorra, se faz necessário o envolvimento de diferentes profissionais, formando redes de apoio, que juntos busquem tornar as escolas comuns acessíveis e assegurar o acesso, permanência, aprendizado e participação dos estudantes Público-Alvo da Educação Especial (PAEE) (BRASIL, 20I5). 
Corroborando o apresentado, Stainback e Stainback (1999) refletem sobre: a importância de que essas redes de apoio sejam constituídas por meio de um princípio unilateral; o reconhecimento das capacidades e potencialidades dos profissionais envolvidos e; que estes compartilhem os saberes, tencionando a partilha de responsabilidades e as melhores estratégias para beneficiar o aprendizado de todos.

Baseados nesses pressupostos, Calheiros (2019) realizou um estudo que apresentou como objetivo analisar o processo de desenvolvimento, implementação, bem como possibilidades e limites dos serviços de uma rede de apoio à inclusão escolar para estudantes com paralisia cerebral. $O$ estudo foi realizado na cidade de Maceió-AL e contou com a amostra de 19 pessoas, destes: diretores, coordenadores, professores de classe comum, professor de educação especial, profissionais de apoio, técnico em educação especial da rede municipal, profissionais de um centro especializado em reabilitação, representante do núcleo de estudos em educação e diversidade, estudante com paralisia cerebral e responsável e pesquisador. Diante dos resultados obtidos, comprovou-se que é de suma importância que as políticas públicas garantam a implementação de redes de apoio diversificadas.

Capellini e Zerbato (2019) pontuam que a educação das crianças, jovens e adultos PAEE não é responsabilidade de um ou dois sujeitos (professor da sala comum e professor de educação especial), mas há uma importante tendência de descentralização, em vista da necessidade de atuação em parceria, como o melhor caminho para o ensino e aprendizado de turmas heterogêneas.

$\mathrm{Na}$ literatura são recomendados diferentes profissionais para compor redes de apoio, porém, nota-se uma crescente presença de um novo personagem na tentativa de garantir a escolarização de estudantes do público-alvo da Educação Especial nas classes comuns de escolas regulares: o chamado Profissional de Apoio Escolar à Inclusão Escolar (PAIE) (MENDES; VILARONGA; ZERBATO, 20I4; LOPES, 2018). O histórico de surgimento desse profissional no Brasil se deu pela demanda de suporte de uma parcela de estudantes PAEE em relação às necessidades de higiene, deslocamento e alimentação, obrigando a contratação de um novo profissional nas escolas para exercer esse papel (SOUZA et al., 2012).

Para Almeida, Siems-Marcondes e Boer (20l4), o profissional de apoio tem uma atuação recente e, por isso, é constatada uma multiplicidade de denominações para essa figura nas escolas, estando entre elas: cuidador, paraprofissional, mediador, monitor, estagiário, profissional de apoio, dentre outros. A literatura aponta, também, perfis e funções diversas, atribuídos de acordo com o contexto no qual estão inseridos (MARTINS, 20II; MENDES; VILARONGA; ZERBATO, 20I4; LEAL, 2015; LOPES, 2018).

$\mathrm{Na}$ legislação educacional nacional, ao longo do tempo, percebem-se mudanças na definição da função e no perfil do PAIE. Na Resolução CNE/CEB n 02/200I, Artigo $8^{\circ}$, por exemplo, este 
profissional era determinado como um suporte ao professor, ou seja, se dava como um serviço de apoio pedagógico especializado, realizado nas classes comuns de ensino (BRASIL, 200I). Porém, com a Política Nacional da Educação Especial na Perspectiva da Educação Inclusiva (BRASIL, 2008), houve mudanças e esse profissional passou a ser chamado de cuidador ou monitor e sua atuação destinou-se ao apoio na alimentação, higiene e locomoção dos estudantes PAEE.

Contudo, a primeira legislação que especifica o papel desse profissional, denominado de profissional de apoio escolar, é a Lei n ${ }^{\circ}$ 13.146, conhecida como Lei Brasileira de Inclusão e Estatuto da Pessoa com deficiência (BRASIL, 20I5), que descreve esse profissional como:

Pessoa que exerce atividades de alimentação, higiene e locomoção do estudante com deficiência e atua em todas as atividades escolares nas quais se fizer necessária, em todos os níveis e modalidades de ensino, em instituições públicas e privadas, excluídas as técnicas ou procedimentos identificados com profissões legalmente estabelecidas (BRASIL, 2015, on-line).

Diante do exposto, conclui-se que quem exerce esse cargo não pode assumir nenhuma função que seja de responsabilidade de um profissional regulamentado, como por exemplo, professores, psicólogos, fonoaudiólogos, dentre outros. Entretanto, ainda há necessidade de uma melhor contextualização desse profissional nos documentos normativos, tendo em vista que eles não abordam, de forma objetiva, o perfil necessário e as atribuições que realmente devem ser desempenhadas por eles. Assim sendo, essas lacunas reconhecidas têm gerado diferentes interpretações, deixando margens para que cada sistema de ensino se organize da forma que lhes for mais conveniente, nem sempre beneficiando os estudantes por esse tipo de apoio.

De fato, Martins (20II) e Lopes (20I8) destacam que, com a ausência de esclarecimentos legais, municípios e estados têm atribuído suas funções e exigido perfis de profissionais de forma autônoma. Em seus estudos, os referidos autores identificaram, atuando como PAIE, profissionais com formação em Ensino Médio, completo ou incompleto, estudantes ou graduados em Pedagogia e, até mesmo, graduados diversos com especialização em Educação Especial, o que configura uma pluralidade na identidade e na função desse profissional na realidade das escolas.

Nessa perspectiva, alguns conflitos e equívocos são identificados na inserção desses profissionais nas escolas. Xavier (2019), por exemplo, encontrou um contexto onde as práticas pedagógicas desenvolvidas na sala de aula comum com os estudantes PAEE estavam sendo realizadas, prioritariamente, pelo PAIE, que exercia funções docentes, contrariando o estabelecido na lei que proíbe que eles desempenhem funções legalmente estabelecidas. Isso ocorre, possivelmente, como estratégia de minimizar investimento de recursos humanos nas políticas locais de inclusão escolar, pois muitas vezes, o PAIE tem sido o único suporte presente dentro de sala de aula, resultando em uma atuação inadequada e, consequentemente, proporcionando práticas que podem ser consideradas como 
desvio de função. Diante disto, é possível identificar a precarização e o barateamento dos profissionais da área da Educação Especial, havendo contratação de profissionais desqualificados e mais baratos para assumirem funções docentes que não são da sua competência.

Além desse cenário, diferentes autores registraram a ocorrência da contratação indiscriminada e aleatória de PAIE para os estudantes PAEE, sem avaliação adequada da demanda e sem critérios para a provisão desse tipo de apoio. Os estudos de Martins (201I) e Xavier (2019) apontaram três situações recorrentes desse contexto: I) exigência da família na luta pelos direitos dos seus filhos; 2) solicitação da escola por ser mais um serviço de apoio, independente da necessidade dos estudantes; 3) judicialização, quando a justiça é quem determina a obrigatoriedade da contratação desse profissional, antes mesmo sem uma avaliação da demanda. Diante disso, questiona-se: quais os motivos usados para justificar a demanda e atribuição dos PAIE para estudantes PAEE que estão sendo escolarizados nas escolas comuns?

Buscando responder tal dúvida, a proposta deste estudo teve como objetivo descrever e analisar motivos alegados para demandar e atribuir Profissionais de Apoio à Inclusão Escolar (PAIE). Justifica-se a import__ ância desse estudo, em vista de contribuir com as discussões contemporâneas envolvendo profissionais pertencentes à rede de apoio que visem contribuir com a escolarização dos estudantes PAEE, como também beneficiar a atuação desses profissionais, tornando mais claros os motivos considerados para a inserção desses sujeitos nas escolas comuns.

\section{Método}

A investigação envolveu um delineamento de estudo de multicasos que, segundo Triviños (1987), é uma variação do estudo de caso, pois enfoca duas ou mais organizações ou sujeitos. A pesquisa envolveu dois estados e cinco municípios, sendo três cidades do Estado da Bahia e duas do Estado de São Paulo. A coleta de dados foi realizada por meio de Grupos Focais (GF) com roteiro semiestruturado.

Gomes (2005) recomenda que o GF seja composto por um grupo de pessoas formado a partir de um critério estabelecido pelo mediador, preferencialmente composto por seis a dez pessoas que possuem experiências e conhecimentos em comum para discussão de um determinado tema. No presente estudo, os grupos focais de PAIE foram compostos em cada um dos cinco municípios. As entrevistas com GF foram utilizadas para ultrapassar os limites das discussões, aflorar diversas dimensões e visões diferentes de cada tema abordado, facilitando a interação entre os participantes (GOMES, 2005).

Antes de iniciar a coleta de dados, o estudo foi submetido ao Comitê de Ética da Universidade Federal de São Carlos, com a apresentação da Carta de autorização, comprovando o assentimento 
dos municípios pesquisados. O estudo foi desenvolvido de acordo com os parâmetros da Resolução do Conselho Nacional de Saúde $n^{\circ} 466$, de 12 de dezembro de 2012, que regulamenta pesquisas envolvendo seres humanos nas ciências sociais aplicadas. Após a aprovação do Comitê de Ética, foi feito um novo contato com a gestão de educação especial dos municípios para a efetivação do convite para a participação. Em cada contexto, o projeto foi apresentado e foi solicitado, aos responsáveis, dados preliminares dos possíveis participantes do estudo para a articulação das próximas etapas. Uma vez identificados os participantes, aqueles que demonstraram interesse assinaram o Termo de Consentimento Livre e Esclarecido (TCLE). Vale ressaltar que durante todo o processo foi assegurada a autonomia e a liberdade dos participantes na pesquisa, sendo garantidas a confidencialidade e a privacidade de suas identidades, dentre outras. Ressalta-se que os dados desse manuscrito foram coletados durante os anos de 2016 e 2017.

Participaram do estudo 30 PAIE que atenderam aos critérios para inclusão: exercer a função de profissional de apoio; estar atuando com alunos PAEE da educação infantil, ensino fundamental I e II e; ter interesse em participar do estudo. O Quadro I apresenta a organização dos dados dos participantes por cidade, destacando-se que foram utilizados nomes fictícios para os municípios e siglas para os participantes, sendo consideradas as letras iniciais das cidades e acompanhamento numérico.

Quadro I - Identificação dos participantes

\begin{tabular}{|c|c|}
\hline Cidade & Grupo Focal/ Participantes \\
\hline Flores & FI-F2-F3-F4-F5-F6 \\
\hline Sexto Elemento & SI-S2-S3-S4- S5-S6 \\
\hline Lince & LI- L2-L3-L4- L5 \\
\hline Santa Clara & SCI- SC2 -SC3-SC4-SC5- SC6- SC7 \\
\hline Chico Lopes & CI-C2-C3- C4-C5-C6 \\
\hline
\end{tabular}

Fonte: Elaboração própria, 2018.

Os participantes foram descritos por cidade conforme será apresentado no Quadro 2 composto por quantidade de PAIE por cidade, o sexo de acordo com a quantidade de participantes ( $F$ - feminino; M - masculino), a idade (em anos), o tempo de atuação como PAIE (em meses e anos), formação inicial e suas experiências profissionais anteriores. 
Quadro 2 - Características dos participantes PAIE de cada município

\begin{tabular}{|c|c|c|c|c|c|c|}
\hline Cidade & $\mathbf{n}^{\circ}$ & $\begin{array}{l}\text { Sexo } \\
\text { (M/F) }\end{array}$ & $\begin{array}{l}\text { Idade } \\
\text { (em } \\
\text { anos) }\end{array}$ & $\begin{array}{l}\text { Tempo } \\
\text { de } \\
\text { atuação } \\
\text { (m-meses } \\
\text { e a-anos) }\end{array}$ & Formação & $\begin{array}{l}\text { Experiências } \\
\text { Anteriores }\end{array}$ \\
\hline $\begin{array}{l}\text { Lince } \\
\text { (BA) }\end{array}$ & 5 & $5 F$ & $22-40$ & $1 \mathrm{a}-3 \mathrm{a}$ & $\begin{array}{l}\text { Ensino Médio completo ou } \\
\text { incompleto, estudantes } \\
\text { (pedagogia, fonoaudiologia, } \\
\text { psicologia), Pedagogia, } \\
\text { Psicologia, Psicopedagogia. }\end{array}$ & $\begin{array}{l}\text { Chaveira, babá, } \\
\text { vendedora, } \\
\text { comerciária. }\end{array}$ \\
\hline $\begin{array}{l}\text { Sexto } \\
\text { Elemento } \\
\text { (BA) }\end{array}$ & 6 & $\begin{array}{l}5 \mathrm{~F} \\
\mathrm{IM}\end{array}$ & $29-53$ & $4 m-4 a$ & Ensino Médio completo. & $\begin{array}{l}\text { Auxiliar de creche, } \\
\text { vendedora em } \\
\text { lanchonete, } \\
\text { rodoviária, caixa de } \\
\text { supermercado. }\end{array}$ \\
\hline $\begin{array}{l}\text { Flores } \\
\text { (BA) }\end{array}$ & 6 & $6 \mathrm{~F}$ & $26-40$ & $9 m-10 m$ & Estagiário de pedagogia. & $\begin{array}{c}\text { Auxiliar } \\
\text { administrativo, } \\
\text { vendedor, } \\
\text { telemarketing, oficina } \\
\text { mecânica, auxiliar em } \\
\text { escola. }\end{array}$ \\
\hline $\begin{array}{l}\text { Santa } \\
\text { Clara } \\
\text { (SP) }\end{array}$ & 7 & $\begin{array}{l}5 F \\
2 M\end{array}$ & $25-45$ & $3 m-6 a 6 m$ & $\begin{array}{c}\text { Ensino Médio, estudante de } \\
\text { Pedagogia, Pedagogia. }\end{array}$ & $\begin{array}{l}\text { Operador de caixa, } \\
\text { comunicação visual, } \\
\text { auxiliar de limpeza, } \\
\text { restaurante, } \\
\text { costureira. }\end{array}$ \\
\hline $\begin{array}{l}\text { Chico } \\
\text { Lopes } \\
\text { (SP) }\end{array}$ & 6 & $6 \mathrm{~F}$ & $\begin{array}{l}28-54 \\
\text { anos. }\end{array}$ & $\mathrm{Ia}-4 \mathrm{a}$ & $\begin{array}{c}\text { Ensino Médio completo e } \\
\text { incompleto, estudantes de } \\
\text { pedagogia. }\end{array}$ & $\begin{array}{l}\text { Call center, salão de } \\
\text { beleza, escritório, } \\
\text { vendedor, babá. }\end{array}$ \\
\hline
\end{tabular}

Fonte: Elaboração própria, 2018.

Constatou-se que os participantes das cinco cidades tinham perfis semelhantes em relação à predominância de mulheres, o que pode ser associado à função do cuidar, envolvida em uma das questões do cargo, que geralmente se relaciona com o gênero e estereótipo feminino. Porém, nas três cidades havia homens no quadro de funcionários.

A idade dos participantes PAIE das cinco cidades variou entre 22 e 54 anos, sendo que os participantes do município de Lince, Flores e Santa Clara eram mais jovens (22 a 45 anos), enquanto os de Sexto Elemento e Chico Lopes eram mais velhos (28 a 54 anos).

O tempo de atuação na função variou de três meses a seis anos e meio, com maior número de participantes com experiência igual ou inferior a quatro anos, o que indica que o aumento de contratação parece ter ocorrido depois da aprovação da LBI. Particularmente no município das Flores, todos atuavam a menos de um ano, o que pode ser justificado pelo regimento do estagiário que 
permite, no máximo, 24 meses de permanência. Em Santa Clara, encontrou-se tanto o participante com o menor tempo de atuação (três meses) quanto aquele com mais experiência na função (seis anos e meio).

Destaca-se, ainda, que o tempo de atuação também parece depender das condições de contratação de cada município. Aqueles que contratavam estagiários, em função da regulamentação própria que limita o tempo máximo de contratação, poderiam apresentar maior rotatividade dos profissionais, tendo como decorrência disso demandas constantes de contratação e treinamento de PAIE.

Em relação ao nível e aos requisitos de escolaridade, cada município apresentou uma diversidade de perfis dos participantes, variando desde participantes com Ensino Médio incompleto até cursos de especialização. Municípios como Lince, Santa Clara e Chico Lopes contratavam como PAIE profissionais com variados níveis de escolaridade, como por exemplo, Ensino Médio incompleto ou completo, estudantes universitários (Pedagogia, Psicologia, Fonoaudiologia), sendo que um deles (Lince) também contratava especialistas em Psicopedagogia. Flores contratava, exclusivamente, estagiários de Pedagogia e Sexto Elemento, apenas profissionais com Ensino Médio.

Quanto às experiências de trabalhos anteriores, a maioria dos participantes das cinco cidades informou não ter relação com a atual função e foram encontradas experiências anteriores de vendedora, atendente de comércio, chaveira, auxiliar (de lanchonete, administrativo, limpeza, restaurante), operador de caixa, costureira, atendente de telemarketing, ajudante (de oficina mecânica, de salão de beleza), rodoviário e operador de call center, entre outras. Em alguns poucos casos, apareceram funções mais próximas à de PAIE, como auxiliar de escola, auxiliar de creche e babá.

\section{Procedimento de análise dos dados}

As reuniões com os grupos de participantes foram gravadas em áudio e os relatos foram transcritos e revisados de acordo com as sugestões de Manzini (2012). A análise de dados ocorreu em três etapas, sendo elas: organização, refinamento e interpretação. Posteriormente às transcrições e revisões, os dados foram categorizados, levando-se em consideração temas emergentes. De acordo com Castro (201I) a categorização pode ser entendida como:

Processo gradual de agrupamento de elementos, conceitos ou mensagens, que vai sendo elaborado no cotidiano da pesquisa. É uma incessante 'ida e vinda' entre o referencial teórico e os dados obtidos, como também um reformular constante ao longo da análise das respostas, de acordo com os dados encontrados e com a teoria que embasa a pesquisa (CASTRO, 20I I, p. 93).

No procedimento de análise dos dados foi utilizado o software ATLAS.ti e foram identificadas cinco categorias de análise, apresentadas a seguir. 


\section{Resultados e Discussões}

Nos relatos dos PAIE foram identificados cinco diferentes justificativas para a contratação desses profissionais para atuarem como suporte aos estudantes PAEE nas escolas. As principais encontradas constam no Quadro 3:

Quadro 3 - Cidades pesquisadas e justificativas de encaminhamento

\begin{tabular}{|c|c|}
\hline Cidades & Justificativas \\
\hline $\begin{array}{c}4 \text { CIDADES } \\
\text { TODAS DA BAHIA, CHICO LOPES (SP), } \\
\text { SANTA CLARA (estagiários- SP) }\end{array}$ & $\begin{array}{l}\text { I- Promover a participação e aprendizagem do aluno na } \\
\text { escola }\end{array}$ \\
\hline $\begin{array}{l}3 \text { CIDADES } \\
\text { (BA) }\end{array}$ & II- Suporte ao comportamento desafiador \\
\hline $\begin{array}{l}3 \text { CIDADES } \\
\text { (BA) }\end{array}$ & $\begin{array}{l}\text { III- Suporte a estudantes com comprometimentos } \\
\text { motores }\end{array}$ \\
\hline $\begin{array}{c}3 \text { CIDADES } \\
\text { FLORES (BA), SANTA CLARA (AVE-SP), } \\
\text { CHICO LOPES (SP) }\end{array}$ & $\begin{array}{l}\text { IV- Suporte aos estudantes com dependência nos } \\
\text { cuidados pessoais (alimentação, higiene) }\end{array}$ \\
\hline $\begin{array}{c}\text { I CIDADE } \\
\text { SEXTO ELEMENTO, LINCE }\end{array}$ & V- Evitar que os alunos PAEE atrapalhem a aula \\
\hline
\end{tabular}

Fonte: Elaboração própria, 2021.

Visualizando o quadro, há uma variedade de percepções sobre as justificativas do encaminhamento e lotação dos PAIE, explicados, a seguir, por ordem de recorrência nas cidades.

I- Promover a participação e aprendizagem do estudante PAEE na escola

Esta foi a justificativa mais encontrada, presente em quatro dos cinco municípios pesquisados e que é justificada pela intenção de evitar a exclusão dos estudantes do PAEE no processo de escolarização, assim como contribuir com a socialização e formação desses estudantes para o futuro. Xavier (2019) apontou em seu estudo que o profissional de apoio era visto como protagonista no processo de inclusão escolar dos estudantes PAEE, pois era ele que se responsabilizava pelo ensino, estabelecimento da rotina, planejamento e execução de atividades a serem realizadas pelos alunos PAEE.

A participante F6 (de Flores), por exemplo, relatou que atuava com uma estudante que ficava isolada, pouco interagia e, consequentemente, estava sendo excluída em sala de aula, pois colegas e profissionais da escola não interagirem com ela e, por isso, justificou a necessidade da presença de uma pessoa para mediar essa situação.

Olhar de professor, Ponta Grossa, v. 24, p. I-18, e-19649.087, 2021.

Disponível em <https://revistas2.uepg.br/index.php/olhardeprofessor> 
Ainda na cidade de Flores, os participantes afirmaram atuar contra a exclusão escolar, pois os estudantes PAEE não conseguiam participar das diferentes atividades escolares sem a presença do profissional de apoio, principalmente em função da superlotação das salas de aula que impediam professores de atenderem a todos os estudantes, como apontou F4:

Em uma sala de 40 alunos você não tem como dar suporte ao aluno que é especial e tem uma deficiência (F4).

Nesse contexto, pode-se identificar que a função do PAIEE de promover a participação e a aprendizagem do estudante PAEE acaba servindo para cobrir a ausência do papel do professor e de outros profissionais da escola na mediação com o aluno PAEE, o despreparo da equipe escolar em manejar situações de preconceito, além de tentar solucionar a falta de condições de trabalho do professor, evidenciado por turmas numerosas que tenham alunos PAEE.

II. Suporte em casos de estudantes com comportamento desafiador

Também foram citadas justificativas, em três das cinco cidades pesquisadas, para casos de estudantes com necessidade do suporte no manejo de comportamentos desafiadores. Os participantes da cidade de Flores informaram que os estudantes "fugiam" da sala, eram inquietos e ficavam dispersos pela escola, sendo assim justificada a necessidade de alguém para mediar essa situação, como afirma F2:

Ela tem um problema cognitivo e precisa de alguém para estar dando esse suporte a ela, ela tem oscilações, tem dias que ela realmente está... Sai da sala toda hora, como o colégio é grande ela vai circular por outras áreas, então precisa de alguém para estar orientando ela. (F2).

Também na cidade Sexto Elemento, os PAIE consideraram como principal justificativa para a contratação do PAIE a necessidade do suporte nos comportamentos desafiadores dos estudantes, ilustrada no relato de S4:

Eu só tenho um e ele tem necessidade, por conta que ele dispersa muito os alunos em sala de aula e ele toda hora quer sair, toda hora quer brincar, quer pegar alguma coisa, toda hora ele sai para ir ao banheiro, toda hora ele vai a uma sala, vai à sala de todo mundo, aí ele tem uma necessidade sim de ter uma pessoa. (S4).

Em Lince também se fez presente a justificativa relacionada aos problemas de comportamento de alunos, porém isso gera preocupação para os próprios PAIE ao se questionarem sobre a real necessidade desse apoio para os estudantes, como é verificado no relato de L2 e L4: 
Esse aluno não precisa de um cuidador e sim de um freio no comportamento (L2).

Acompanho um aluno por conta da falta de educação dele, falta de acompanhamento dos pais de chegar junto, eu não precisaria ficar com ele o tempo todo ali (L4).

Alguns PAIE informaram ter solicitado remanejamento quando consideravam o suporte ao aluno desnecessário. Em alguns casos, tiveram sua opinião respeitada pela direção da escola, enquanto outros alegaram que suas opiniões foram desconsideradas pela gestão e eles, consequentemente, foram mantidos junto com os alunos que não apresentavam necessidade de suporte.

III- Suporte pedagógico a estudantes com comprometimento motor

Outro motivo de encaminhamento do PAIE identificado foi relacionado ao suporte para os estudantes com prejuízos motores, a exemplo de limitações nos membros superiores ou inferiores que impediam o acesso aos materiais básicos pedagógicos, como ocorreu na cidade de Lince.

Ele necessita de uma pessoa para ajudar na hora da atividade, a pegar o lápis, o livro para folhear [...] então ele é uma pessoa que realmente precisa mesmo de cuidador, tem algumas coisas que ele faz sozinho, ele sai da cadeira, a maioria das atividades, ele precisa (L2).

$\mathrm{Na}$ cidade de Flores foi citada a função de escriba para os PAIE junto aos estudantes que apresentavam comprometimento e dificuldades na escrita. Essa função consistia em copiar e transcrever as respostas dos alunos, o que facilitava a participação efetiva deles no processo de aprendizagem e acompanhamento da turma. Como relatou um PAIE de Flores:

Eu sento e só escrevo para uma aluna mesmo, no meu caso ela tem que me dar as respostas e eu tenho que copiar, as coisas no quadro eu vou copiando e ela vai respondendo (F4).

Neste caso, existem outras possibilidades de apoio que poderiam ser mais adequadas e gerar mais benefícios por favorecer a autonomia, como uso dos recursos de Tecnologia Assistiva (TA) que, segundo o Comitê de ajudas técnicas (CAT) (2007), é:

Uma área do conhecimento, de característica interdisciplinar, que engloba produtos, recursos, metodologias, estratégias, práticas e serviços que objetivam promover a funcionalidade, relacionada à atividade e participação, de pessoas com deficiência, incapacidades ou mobilidade reduzida, visando sua autonomia, independência, qualidade de vida e inclusão social (CAT, 2007, on-line).

Deste modo, o uso da TA na escola favorece a autonomia do estudante e a participação nas atividades, conforme citado no estudo de Lino, Gonçalves e Lourenço (20I5) sobre essa prática:

Deve ser priorizado o uso da Tecnologia Assistiva para certas atividades, como as de vida diária, o estabelecimento da comunicação e a participação efetiva em sala

Olhar de professor, Ponta Grossa, v. 24, p. I-18, e-19649.087, 2021.

Disponível em <https://revistas2.uepg.br/index.php/olhardeprofessor> 
de aula, pois a criança pode se deparar com dificuldades e até com a privação das diversas experiências oferecidas às demais devido à sua condição física, intelectual e/ou sensorial (LINO; GONÇALVES; LOURENÇO, 2015, p. 5, grifo nosso).

Ressalta-se que a TA é uma estratégia facilitadora para o processo de ensino e aprendizagem na escola, contudo cada aluno tem sua especificidade e deve-se ter cuidado ao definir o produto, o recurso, a metodologia, estratégia, prática e o serviço mais adequado para cada um, sendo necessária uma avaliação multidisciplinar para essa definição.

Existem alguns recursos de acessibilidade específicos para pessoas com comprometimento motor dos membros superiores, que se enquadram nas categorias de TA definidas por Bersch (2017) como: "auxílios para a vida diária e vida prática", a exemplo dos adaptadores de material pedagógico, como engrossadores de lápis, suporte da tesoura, entre outros; "Recursos de acessibilidade ao computador", que são hardwares e softwares que tornam o computador acessível para as pessoas que possuem algum tipo de limitação sensorial e motora.

IV. Suporte a estudantes com dependência nos cuidados pessoais básicos

Nos municípios de Santa Clara (SP), Flores (BA) e Chico Lopes (SP), os participantes pontuaram as justificativas de encaminhamento voltadas às necessidades de os estudantes PAEE precisarem de suporte na locomoção, higiene e alimentação. Em Santa Clara, os PAIE relataram que essas atividades não poderiam ser realizadas pelos professores, já que estes não poderiam sair da sala para acompanhar os estudantes e a escola não possuía funcionários para dar esse suporte.

O professor não tem como ajudar aquele aluno que necessita de atenção, pois tem um número grande de alunos, como que o professor a sair para levar o aluno ao banheiro? (SC2).

Tais dados relatados estão de acordo com a Lei Brasileira de Inclusão (BRASIL, 20I5) que estabelece o papel desse profissional relacionado ao suporte nos cuidados básicos, alimentação, higiene e locomoção dos estudantes PAEE que tiverem necessidade desse apoio. Dado também constatado nos estudos de Lopes (2018), Martins (2011) e Xavier (2019), quando questionados os participantes sobre as funções desempenhadas nas salas comuns junto aos estudantes PAEE.

V. Evitar que os alunos PAEE atrapalhem a aula

Também foi apresentado como justificativa o apoio em sala para que os estudantes PAEE não atrapalhassem os colegas, situação que, segundo os participantes, poderia prejudicar as outras crianças, conforme a fala de S5:

Olhar de professor, Ponta Grossa, v. 24, p. I-18, e-19649.087, 2021.

Disponível em <https://revistas2.uepg.br/index.php/olhardeprofessor> 
O professor ou bem dá aula ou ele cuida do autista, se ele parar para cuidar do autista ele vai empatar os outros alunos, então tem que ter um profissional específico para isso (S5).

Em Lince, a percepção é semelhante à relatada, sendo que os estudantes são retirados da sala de aula para não atrapalharem os colegas em momentos de comportamentos inadequados, conforme a fala de $L 2$ :

O que passavam para mim, era para tirar a criança da sala o tempo todo (L2).

O relato de $L 2$ tem semelhança com o de $L 4$, que também afirmou ter dificuldades em relação à retirada do aluno, pois em alguns momentos percebia a necessidade de sair, mas, ao retornar, o professor não concordava, preferia que o aluno permanecesse do lado de fora:

Vou para o pátio, a acalmo um pouco, mas não fico muito tempo fora da sala de aula com ela, a professora da sala de aula fala, tem que sair com ela um pouco, mas eu saio, mas ela se acalma e eu volto, a professora pergunta, já voltou? Eu falo que ela tem que se acostumar com ela, ela grita, mas ela vai se acalmar e eu fico na sala de aula com ela (L4).

Nos excertos apresentados é evidenciada uma latente preocupação do favorecimento da escola, do professor e dos demais estudantes, sendo negligenciado o direito à educação do estudante PAEE, justificado pelo fato desses alunos atrapalharem a aula e incomodar os colegas e professores. Diante disso, se faz necessário a presença de um novo profissional para mediar essas situações.

Considera-se que a retirada do estudante PAEE da sala de aula é uma prática inadequada, em vista de nem sempre ser a melhor estratégia, sem considerar as especificidades e condições dos alunos. Ressalta-se que o direito à educação é de todos e é importante que nenhum estudante tenha prejuízo durante a escolarização, mas as tomadas de decisões precisam ser responsáveis e com objetivos direcionados para que se oportunize um ambiente favorecedor e benéfico para todos.

A retirada de sala sem nenhum tipo de direcionamento após a ação, sem um trabalho elaborado e relacionado aos comportamentos inadequados, pode não ser eficaz e, pelo contrário, pode intensificar o comportamento de esquiva do aluno da sala de aula. Nesse tipo de prática, é preciso avaliar antes a necessidade e ter o cuidado para que essa ação não se torne uma rotina e prejudique o aluno, pois essa prática pode ferir o direito de acesso e permanência na escola, além de poder intensificar o problema. No relato de $L 3$ foi possível identificar a retirada de sala como parte da sua função, conforme relato a seguir:

A menina quando ela tinha as crises, chegavam para mim e falavam, leva ela para o parque! Então todas as vezes que ela dava uma crise, levava para o parque, essa orientação da gestão, se ela estiver incomodando e atrapalhando o rendimento da turma, leve para o parque! A preocupação da gestão era não incomodar os demais 
e não atrapalhar o desenvolvimento da turma, do que a importância da educação da própria aluna (L3).

A situação relatada é preocupante, pois foi apresentada como função de um profissional que foi contratado para "facilitar a inclusão do aluno", porém foi percebido que a real necessidade estava vinculada à preocupação de esse estudante não atrapalhar os demais colegas e, consequentemente, o andamento da aula. Dessa forma, o suporte mudou de foco e o que era para o aluno PAEE virou suporte para a escola e o PAIE acaba "mascaradamente" sendo utilizado para resolver "problemas" gerados pela inclusão.

Em Santa Clara, houve relato semelhante, um PAIE afirmou que a diretora da escola o mandava dar voltas no pátio com a aluna, pois ninguém sabia lidar com ela. A estagiária também tinha dificuldades com a aluna e relatou que, mesmo não sendo seu papel, entrava na sala e acomodava a aluna, pois considerava desumano o fato da criança estar precisando de ajuda e ninguém se importar. A PAIE afirmou, ainda, que ao entrar na sala a aluna ficava agitada pelo fato de não ter ocupação, não ter atividade, enquanto todo mundo fazia algo e ela ficava excluída.

\section{Conclusões}

A presença dos PAIE nas escolas comuns é uma realidade cada vez mais frequente, todavia se faz necessário compreender os motivos pelos quais as famílias e educadores consideraram a necessidade de suporte desses profissionais aos estudantes PAEE que estão sendo escolarizados em classes comuns de escolas regulares.

Considerando o problema de pesquisa relacionado às justificativas utilizadas para atribuição de suporte de PAIE aos estudantes PAEE nas escolas comuns, foi possível mapear cinco categorias diferentes, dentre elas: questões relacionadas à necessidade de promover a participação e aprendizagem, apoiar estudantes com comportamento desafiadores, oferecer suporte pedagógico específico a estudantes com dificuldades motoras, oferecer ajuda em cuidados pessoais básicos (locomoção, higiene e alimentação) e evitar que estudantes PAEE atrapalhem suas turmas retirando o estudante da sala.

Em síntese, foi possível identificar um cenário que oscila entre justificativas adequadas acerca da necessidade de suporte para o estudante PAEE e inadequadas, que são aquelas que visam suprir a ausência de suportes mais adequados, como por exemplo, de recursos de tecnologia assistiva, professores de Educação Especial, consultorias de profissionais da equipe multidisciplinar e, até mesmo, para cobrir lacunas na formação de professores.

A literatura pontua que este é um suporte importante para favorecer a participação e a aprendizagem de alguns estudantes PAEE nas escolas, entretanto, os dados permitem questionar, em 
muitos casos, a real necessidade dos estudantes de ter este serviço, assim como, os argumentos utilizados pelos gestores, professores e famílias que demandam esse profissional.

Em relação à escola, identificou-se que, em muitos casos, esse profissional é solicitado por causa da escassez de recursos humanos para atender as especificidades escolares e isso se dá pelo fato de o município possuir uma rede de apoio reduzida. Assim, sendo o PAIE uma das únicas possibilidades de suporte nas escolas e o mais barato, este acaba sendo visto como personagem principal para garantir a política de inclusão escolar, conforme também apontam outros estudos (ASSALI, 2006; GIANGRECO, 2010).

Porém, é preciso considerar que esse direito não implica necessariamente em obrigação de prover esse recurso para todo e qualquer estudante PAEE, aspecto que precisa ser avaliado por diferentes profissionais e famílias. Essa situação entre ter o direito e ser garantida a necessidade tensiona a relação entre escolas e famílias e tem gerado o crescente de casos de judicialização da educação envolvendo estudantes PAEE.

É fato que se os direitos e serviços não são efetivados, isso motiva as famílias a buscarem os órgãos responsáveis (Ministério Público, Defensoria Pública, Segurança Pública, Conselho Tutelar, Conselho da Criança e do Adolescente) e tem sido a nova fonte de indução da solicitação de profissionais de apoio (SERRA, 20I7).

A partir dos encaminhamentos para os referidos órgãos, boa parte das ações são atendidas, fazendo com que seja realizada a oferta obrigatória da presença do PAIE por imposição desses órgãos. Serra (2017) aponta que o caminho jurídico nem sempre é o melhor e defende que, por força da lei, nem sempre os resultados pedagógicos são os melhores.

A necessidade da presença do PAIE tem sido justificada pela necessidade de prover auxílio ao aluno PAEE, de apoiar o professor e até para favorecer os colegas. De fato, parece haver casos em que a atribuição é desnecessária, nos quais o aluno não precisa desse tipo de apoio e, mesmo, casos em que o próprio aluno não deseja esse tipo de suporte.

Essas são situações que mostram a necessidade de comprometimento e seriedade no processo de avaliação, encaminhamento e acompanhamento do trabalho desse profissional. A falta de avaliação educacional criteriosa e responsável, consequentemente, também gera esses tipos de encaminhamentos desnecessários, muitas vezes sem o estudante apresentar o perfil para ter o PAIE como apoio. Dessa forma, o PAIE ocupa um espaço de solução da inclusão por ser o único serviço disponível na rede, em algumas situações, desviando função. São situações preocupantes, pois o encaminhamento equivocado desse profissional pode trazer diversos prejuízos para os estudantes, podendo interferir no seu desenvolvimento e autonomia dentro da escola. Por isso, é importante avaliar a necessidade de cada estudante antes de fazer o encaminhamento, assim como, vale ressaltar 
que em algumas situações esse profissional poderá ser temporário, sendo necessário a reavaliação e o acompanhamento deste serviço de apoio constantemente.

Nesse sentido, orienta-se que os órgãos responsáveis reflitam sobre os critérios a serem utilizados para a definição de casos que necessitem efetivamente de um acompanhamento mais proximal desse profissional. Uma alternativa seria a busca pela implementação da avaliação biopsicossocial, prevista na LBI, e até hoje não implementada, o que resultaria no planejamento educacional individualizado para fundamentar a tomada de decisões sobre a atribuição ou não desse tipo de suporte.

Concluindo, pode-se perceber uma fragilidade na elegibilidade do público a ser acompanhado pelos PAIE, lembrando que a atribuição deste tipo de profissional aumenta o estigma do estudante e coloca no aluno PAEE o foco da dificuldade que muitas vezes é decorrente de políticas de inclusão escolar precárias.

\section{Referências}

ALMEIDA, M. A.; SIEMS-MARCONDES, M. E. R.; BOER, W. O Cuidador de Pessoas com Deficiência: um olhar a partir da perspectiva educacional. In: FREITAS, D. B. A. P.; CARDOZO, S. M. S. (Org.). Inclusão e diferenças: ressignificando conceitos e práticas. Boa Vista: Editora da Universidade Federal de Roraima, 20I4, p. I25-143.

ASSALI, A. M. Inclusão escolar e acompanhamento terapêutico: possibilidade ou entrave? In: Psicanálise, Educação e Transmissão. São Paulo: USP, ano 6, 2006. Disponível em: http://www.proceedings.scielo.br/scielo.php?script=sci_arttext\&pid=MSC0000000032006000 I000 I $7 \&$ Ing=en\&nrm=abn Acesso em: 18 nov.2021.

BERSCH, R. Introdução à Tecnologia Assistiva. Porto Alegre: Assistiva, 2017. Disponível em: http://www.assistiva.com.br/Introducao\%20TA\%20Rita\%20Bersch.pdf. Acesso em: 30 set. 2021.

BRASIL. Lei n 13.005, de 25 de junho de 2014. Aprova o Plano Nacional de Educação - PNE e dá providências. Brasília, 2014. Disponível em: http://pne.mec.gov.br//8-planos-subnacionais-deeducacao/543-plano-nacional-de-educacao-lei-n-I3-005-20I4. Acesso em: 27 maio 2019.

BRASIL. Lei $\mathbf{n}^{\circ}$ 13.146, de 6 de julho de 20 I5. Institui a Lei Brasileira de Inclusão da Pessoa com Deficiência (Estatuto da Pessoa com Deficiência). Brasília, 2015. Disponível em: http://www.planalto.gov.br/ccivil_03/_ato2015-2018/20I5/lei/l13I46.htm. Acesso em: 06 maio 2019.

BRASIL. Política Nacional da Educação Especial na Perspectiva da Educação Inclusiva. Brasília, 2008. Disponível em: http://portal.mec.gov.br/arquivos/pdf/politicaeducespecial.pdf. Acesso em: 07 jun. 2019.

BRASIL. Resolução CNE/CEB N², de I I de setembro de 200 I. Institui Diretrizes Nacionais para a Educação Especial na Educação Básica. Brasília, 200I. Disponível em: http://portal.mec.gov.br/cne/arquivos/pdf/CEB020I.pdf. Acesso em: Acesso em: 27 maio 2019. 
CALHEIROS, D. S. Rede de apoio à escolarização inclusiva na educação básica: dos limites às possibilidades. 2019, 204f. Tese (Doutorado em Educação Especial) - Universidade Federal de São Carlos, São Carlos, 2019. Disponível em: https://repositorio.ufscar.br/handle/ufscar/I I 292?show=full. Acesso em: 15 set. 2021.

CAPELLINI, V. L. M. F.; ZERBATO, A. P. O que é o ensino Colaborativo? São Paulo: Edicon, 2019.

CASTRO, S. F. Ingresso e permanência de alunos com deficiência em universidades públicas brasileiras. 20I I, Tese (Doutorado em Educação Especial) - Universidade Federal de São Carlos, São Carlos, 20I I. Disponível em: https://repositorio.ufscar.br/handle/ufscar/2878?show=full. Acesso em: 16 set. 2021 .

CAT, Comitê de Ajudas Técnicas, Secretaria Especial dos Direitos Humanos da Presidência da República Ata da Reunião VII. 2007. Disponível em: http://www.infoesp.

net/CAT_Reuniao_VII.pdf. Acesso em: 30 set. 202I.

GIANGRECO, M. F. One-to-One Paraprofessionals for Students With Disabilities in Inclusive Classrooms: Is Conventional Wisdom Wrong? Intellect and Developmental Disabilities, v. 48, n. I, p. I-I3, fev 20I0. DOI: 10.I352/I934-9556-48.I.I. Disponível em:

https://pubmed.ncbi.nlm.nih.gov/205038I3/. Acesso em: 23 set. 2021 .

GOMES, A. A. Apontamentos sobre a pesquisa em educação: usos e possibilidades do grupo focal.

EccoS Revista Científica. São Paulo, v. 7, n. 2, p. 275-290, jul./dez. 2005. DOI:

10.5585/eccos.v7i2.417. Disponível em:

https://www.researchgate.net/publication/26504I38_Apontamentos_sobre_a_pesquisa_em_educaca o_usos_e_possibilidades_do_grupo_focal. Acesso em: 22 set. 2021.

LEAL, M. V. S. Concepções do Acompanhante Terapêutico acerca da sua atuação na rede pública municipal de ensino de Teresina. 20I5, I4If. Dissertação (Mestrado em Educação) Universidade Federal do Piauí, Teresina, 2015. Disponível em:

https://repositorio.ufpi.br/xmlui/handle//23456789/I I26. Acesso em: I2 set. 202 I.

LINO, C. C. A.; GONÇALVES, A. G.; LOURENÇO, G. F. O uso de recursos de Tecnologia Assistiva no Atendimento Educacional Especializado: considerações sobre a sala de recursos multifuncionais e escolas especializadas. Temas sobre Desenvolvimento, v. 20, n. I I0-I I, p. 98-I 08, jan. 2015.

Disponível em:

https://www.researchgate.net/publication/305692379_O_uso_de_recursos_de_tecnologia_assistiva_ no_Atendimento_Educacional_Especializado_consideracoes_sobre_a_sala_de_recursos_multifuncio nais_e_escolas_especializadas. Acesso em: 30 set. 2021 .

LOPES, M. M. Perfil e atuação dos profissionais de apoio à inclusão escolar. 2018. 169f. Dissertação (Mestrado em Educação Especial) - Universidade Federal de São Carlos, São Carlos, 2018. Disponível em: https://repositorio.ufscar.br/handle/ufscar/9899?show=full. Acesso em: 10 set. 2021.

MANZINI. E, G. Uso da entrevista em dissertações e teses produzidas em um programa de pósgraduação em educação. Revista Percurso-NEMO, Maringá, v. 4, n. 2, p. I49-I7I, 2012.

Disponível em: https://periodicos.uem.br/ojs/index.php/Percurso/article/view/49548. Acesso em: 29 ago. 2021 . 
MARTINS, S. M. O profissional de apoio na rede regular de ensino: a precarização do trabalho com os alunos da educação especial. 20I I, I68f. Dissertação (Mestrado em Educação) - Universidade Federal de Santa Catarina, Florianópolis. 20I I. Disponível em:

https://repositorio.ufsc.br/handle/I23456789/95218. Acesso em: 10 set. 202I.

MENDES, E. G.; VILARONGA, C. A. R.; ZERBATO, A. P. Ensino Colaborativo como apoio a inclusão: unindo esforços entre educação comum e especial. São Carlos: EdUFSCar, $20 \mid 4$.

SERRA, D. A educação inclusiva em tempos de judicialização do estado: o cotidiano das escolas com a lei Brasileira de inclusão - n 13.I46/20I5. Polêmica-Revista Eletrônica Uerj, v. I7, n. I, p. 27 35, janeiro, fevereiro e março 2017. DOI: https://doi.org//0.12957/polemica.2017.28294. Disponível em: https://www.e-publicacoes.uerj.br/index.php/polemica/article/viewFile/28294/20330. Acesso em: 30 set. 2021 .

SOUZA, A. C. de; BEZERRA, G.; BEZERRA, M. A inclusão escolar no município de Paranaíba (MS): Reflexões sobre a atuação profissional do monitor de alunos com deficiência. Revista Pedagógica. Chapecó, v. I4 n. 29, p. 635-664, jul./dez. 20I2. DOI: https://doi.org/I0.22196/rp.vI4i29.I467.

Disponível em: http://bell.unochapeco.edu.br/revistas/index.php/pedagogica/article/view/I467. Acesso em: 28 out. 2020.

STAINBACK, S.; STAINBACK, W. Inclusão: um guia para educadores. Porto Alegre: Artmed, 1999.

TRIVIÑOS, A. N. S. Introdução à pesquisa em ciências sociais a pesquisa qualitativa em educação. São Paulo: Atlas, 1987.

XAVIER, S. A. Um olhar sobre a prática de profissionais de apoio à alunos com deficiência da rede municipal de ensino do Recife. 2019. Dissertação (Mestrado em Educação) -

Universidade Federal de Pernambuco, Recife, 2019, I56f. Disponível em:

https://repositorio.ufpe.br/handle/I23456789/38606. Acesso em: I3 set. 202 I

Recebido em: 01 de outubro de 2021.

Versão corrigida recebida em: 03 de novembro de 2021 .

Aceito em: 03 de novembro de 2021.

Publicado online em: 03 de dezembro de 2021.

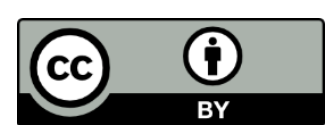

Olhar de professor, Ponta Grossa, v. 24, p. I-18, e-19649.087, 2021.

Disponível em <https://revistas2.uepg.br/index.php/olhardeprofessor> 